\title{
EFFECT OF GLYCYRRHIZINIC ACID ON THE ELECTROLYTE METABOLISM IN ADDISON'S DISEASE
}

\author{
By J. GROEN, ${ }^{1}$ H. PELSER, ${ }^{2}$ M. FRENKEL, ${ }^{3}$ C. E. KAMMINGA, 4 AND \\ A. F. WILLEBRANDS 5 \\ (From the Second Medical Service of the Wilhelmina-Gasthuis in Amsterdam, The
Netherlands)
}

(Submitted for publication July 26, 1951 ; accepted October 15, 1951)

The crude watery extract of the roots of Glycyrrhiza glabra, commonly called licorice, has been proved to produce sodium and chloride retention and increased potassium excretion in normal individuals (1) and in a patient with Addison's disease (2). The typical taste of licorice is due to the presence of glycyrrhizin, the ammonium salt of glycyrrhizinic acid. The substance was shown by Borst and his coworkers (1) to be the active principle responsible for the effect of licorice extract on the electrolyte metabolism in normal individuals. In this paper we wish to present the results of electrolyte balance studies in a patient with Addison's disease during treatment with ammonium glycyrrhizinate.

\section{CASE REPORT}

A 44-year-old typewriter engineer was admitted in April 1946 for the first time. He gave a history of mild attacks of pulmonary tuberculosis with pleurisy when 16, 20 , and 25 years old. Since then he had remained symptom-free until a year before admission when he had noticed fatigue with occasional vomiting and diarrhea. He had developed an aversion for milk but an increased appetite for salted foods. It had been noticed that his skin had become much darker.

On clinical examination he appeared in a moderate nutritional state. There was marked pigmentation of the skin and several dark spots were seen on the oral mucous membrane. There was also an old bilateral fibrous pulmonary lesion. The blood pressure was 100/ 60. The water excretion test of Robinson, Power, and Kepler (3) showed a disturbance of water excretion. The blood sugar tolerance curve after $\mathbf{5 0}$ grams of glucose by mouth did not rise above $122 \mathrm{mg} . \%$.

A diagnosis of Addison's disease was made; the patient

\footnotetext{
1 Senior Physician, Head of the Second Medical Serv-

2 Resident in Medicine.

3 Junior Physician to the Second Medical Service.

4 Research Associate, holding a grant from Organon Laboratories, Inc.

5 Biochemist to the Second Medical Service.
} ice. was treated with desoxycorticosterone acetate (DCA) and was discharged in a satisfactory condition after one month of observation.

He then remained under ambulatory control on a daily maintenance dosage of $3 \mathrm{mg}$. DCA, intramuscularly. On our request he appeared willing to be readmitted for a study of the effect of licorice and its components on his condition.

He was readmitted February 28, 1951. The clinical findings were unchanged, but his blood pressure was now 150/70. A "Thorn test" (4) after injection of 25 mg. ACTH showed no effect on eosinophils and only a slight drop in lymphocytes, which was in agreement with the previous diagnosis. The patient was placed on a balance diet and bed rest. Probably as a result, the blood pressure dropped somewhat. During the ensuing weeks it fluctuated between 115 and 140 systolic, and 70 and 90 diastolic.

\section{BALANCE STUDIES}

After the patient had had an opportunity to get acclimatized, balance studies were started on March 8, 1951. The results are presented in Figures 1-3. For the first three days he appeared to be in marked positive sodium and chloride balance, so that the administration of DCA was reduced to $2.5 \mathrm{mg}$. per day. For the next six days the patient still remained in a somewhat positive sodium and chloride balance; the potassium balance was practically in equilibrium.

During the next period a daily amount of 2 grams of ammonium glycyrrhizinate was given by mouth, while the patient received his ordinary injection of DCA. ${ }^{6}$ In the next three days there appeared to be an increase in sodium and chloride retention, and the body weight increased from 64 to $65.3 \mathrm{Kg}$. During the next period of three days DCA was reduced to $2 \mathrm{mg}$. without appreciable influence on the sodium, chloride or potassium balance. Again three days later, DCA was

\footnotetext{
- Ammonium glycyrrhizinate 20 , added water $300,2 \times$ 15 cc. per day.
} 
reduced to $1 \mathrm{mg}$. daily, while the amount of glycyrrhizinate was increased to 3.3 grams per day. Sodium and chloride balances now seemed to approach equilibrium, which encouraged us during the next period to increase the amount of ammonium glycyrrhizinate to 3.6 grams daily and at the same time to stop the administration of DCA completely. When this was done, sodium and chloride balances remained slightly positive while the potassium balance was slightly negative. This condition was maintained for six days. A further increase of the amount of glycyrrhizinate to
4 grams for another three days had no additive effect.

The preparation of ammonium glycyrrhizinate which we had used until then was a brown, impure substance which had been obtained commercially. We now had the opportunity to administer to this patient a preparation of potassium glycyrrhizinate which had been prepared by Dr. de Jong, pharmacist to the Binnengasthuis, and which had been shown by Dr. Borst and his group to produce sodium and chloride retention and increase potassium excretion in a normal in-

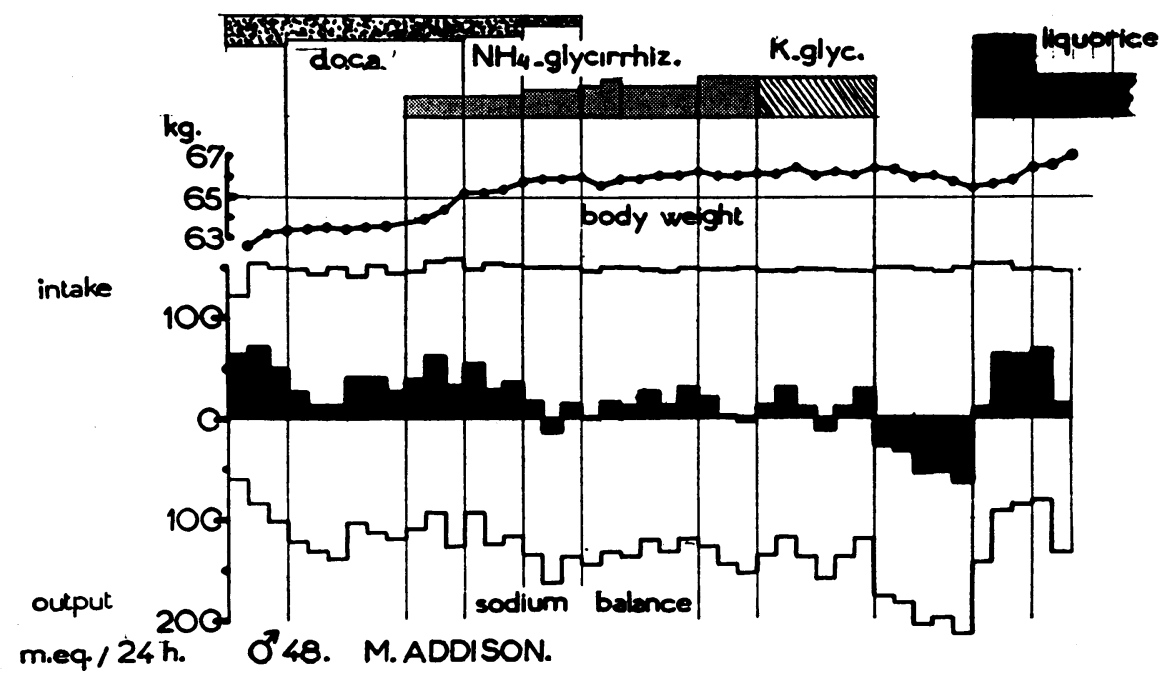

Fig. 1. Sodium Balance Per Day

Sodium intake is represented above the zero line, urinary output below the line. The difference is represented in black either above (positive balance) or below (negative balance) the line.

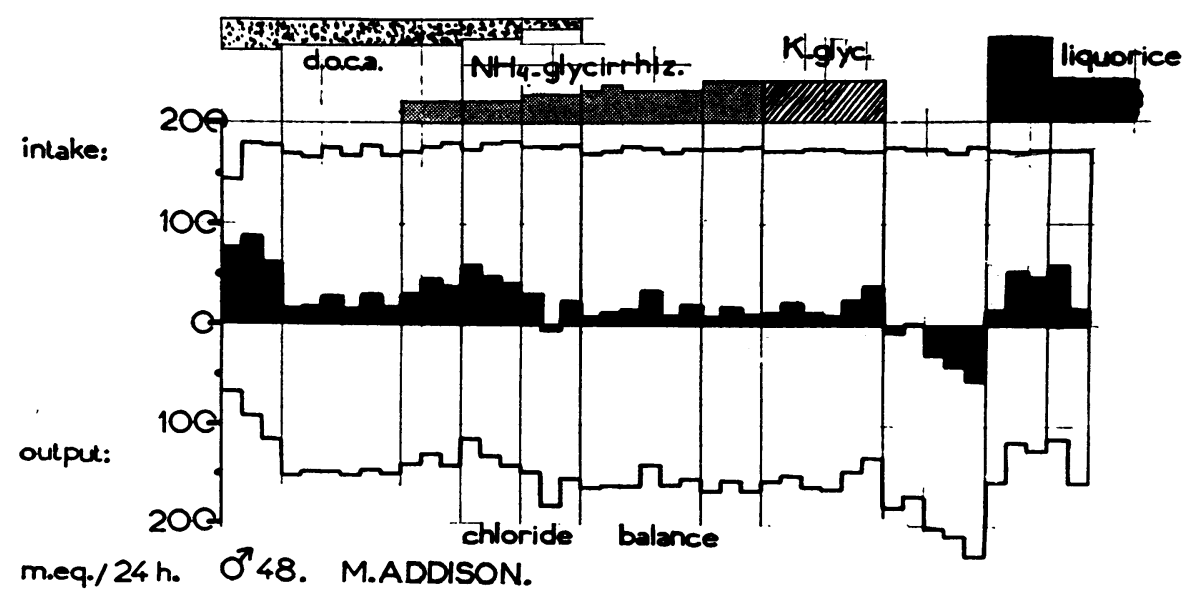

Fig. 2. Chloride Balance

(See legend to Figure 1 for explanation) 


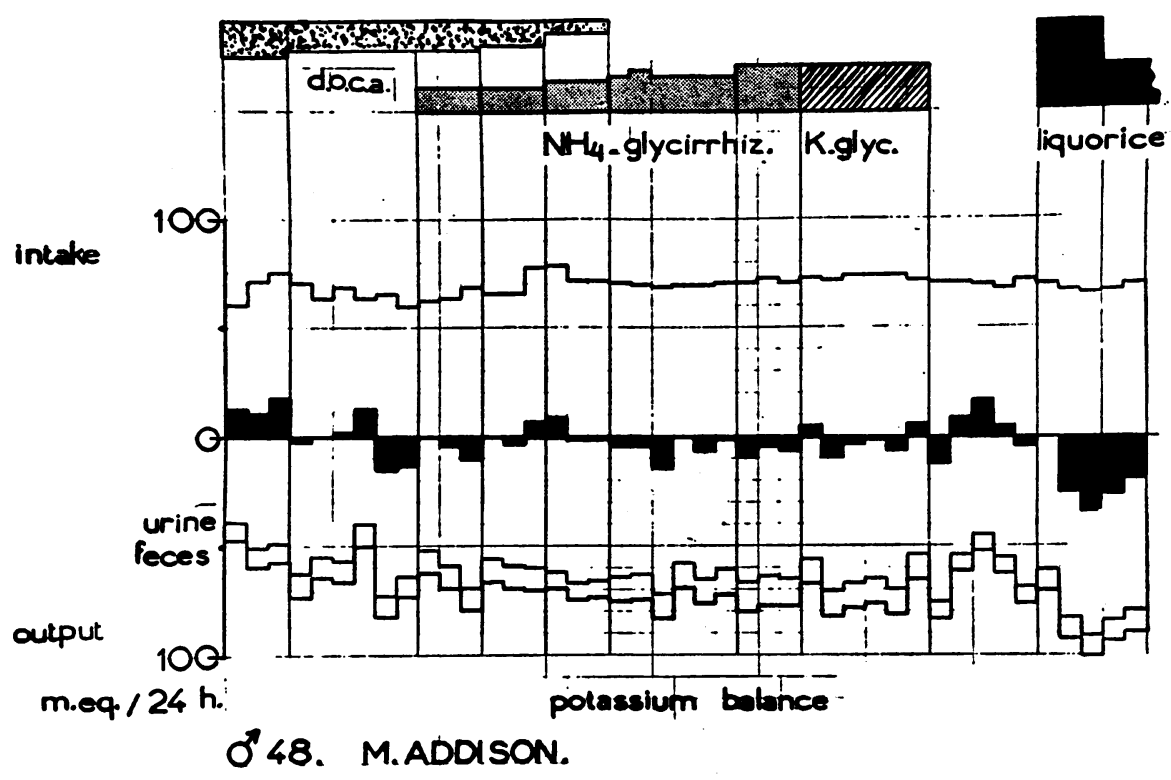

Fig. 3. Potassium Balance

(See legend to Figure 1 for explanation)

dividual. ${ }^{7}$ This substance was still impure certainly, but it was almost white in color and doubtless considerably purer than the preparation used previously.

During the following period, then, the patient received 4 grams of this reprecipitated potassium glycyrrhizinate, redissolved for this purpose by the addition of ammonia. The slightly positive chloride and sodium balances and slightly negative potassium balance were maintained on this preparation. All this time the patient's weight remained constant and regular chemical analyses of the serum revealed normal values for the urea, sodium, potassium, chloride, bicarbonate, hemoglobin, and serum proteins. Thus, this patient with Addison's disease was kept in electrolyte equilibrium and in satisfactory clinical condition for 15 days with no other treatment than the oral administration of the ammonium or potassium salt of glycyrrhizinic acid.

In the next period the administration of glycyrrhizinate was stopped. The sodium balance reacted immediately by a sharply increased excretion and the chloride balance dropped also, but became negative only two days later. The potassium balance reacted one day later and reversed

7 We are indebted to Dr. de Jong and Dr. Borst for their cooperation in this work. into a clearcut retention. The body weight decreased and the patient lost $1 \mathrm{Kg}$. during the next five days.

His clinical condition also deteriorated. He had vague abdominal complaints, experienced fatigue and nausea, and had a sallow complexion. At the end of five days the serum potassium and serum sodium were still normal, but the hemoglobin concentration which had before fluctuated between 11 and 12.6 grams $\%$, had risen to 13.3 grams $\%$ as a first indication of hemoconcentration. The patient, who had been very cooperative until now, began to ask for treatment and as the balance studies had definitely shown that the electrolyte equilibrium became grossly disturbed after stopping the glycyrrhizinate administration, we felt that we were not justified in prolonging this experiment.

On March 18th the patient was given crude licorice extract, 40 grams per day. The sodium and chloride balances reacted immediately and the next day there was a marked retention of these electrolytes. The potassium balance also reacted, but again not until one day later. The body weight increased by $1.3 \mathrm{Kg}$. during the next three days.

After three days it was considered better to reduce the amount of licorice to 20 grams per day. With this treatment the patient remained in good condition; he was discharged five days later and 
is at present back at work. His blood chemistry is normal, his blood pressure within normal limits, and he maintains that he feels even better than during the administration of DCA. At the time of writing (June 1st), almost three months after the DCA medication was discontinued, his satisfactory condition continues.

\section{DISCUSSION}

The present observation seems to prove that glycyrrhizinic acid, through its action on electrolyte metabolism, can replace DCA for the treatment of Addison's disease. Borst's observation that a licorice extract, from which glycyrrhizinic acid has been precipitated, loses its activity, together with the findings in the above case, offers evidence that glycyrrhizinic acid is indeed the active principle through which crude extract of licorice exerts its action. In contrast to the activity of the crude licorice extract, which took a few days before it manifested itself and which seemed to last for a few days after licorice was withdrawn (2), glycyrrhizinic acid manifested its action on sodium and chloride metabolism promptly; the effect on potassium excretion or retention showed a lag of one day.
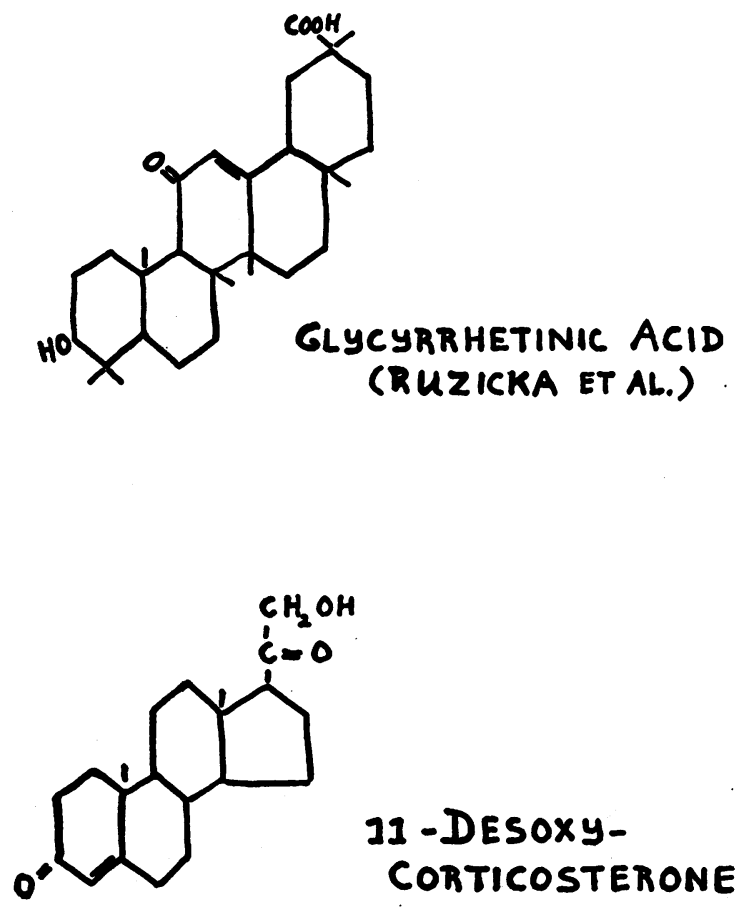

11 -DESOXY-

CORTICOSTERONE

Frg. 4
We have to admit that the best preparation of glycyrrhizinic acid which was used in this investigation was still impure. But it had been reprecipitated four times without appreciable loss of activity which makes the chances considerably smaller that some impurity might be operative.

Glycyrrhizinic acid is a combination of glucuronic acid and glycyrrhetinic acid. The chemical nature of this substance has been investigated by Bergmann (5) and Ruzicka and Leuenberger (6, 7). The structural formula is given in Figure 4. It is a polyterpene compound (more specifically a Triterpenoid) a part of which, through the presence of one $\mathrm{OH}$ group and one $\mathrm{O}$-atom in position 11 , suggests a certain resemblance to the phenantrene part of the steroid series, to which desoxycorticosterone belongs. It would be a mere speculation to ascribe the similarity in physiological action to this partial resemblance in structure, although this is a point well worth following up. It should not be forgotten, however, that even if the physiological action is the same, the amount of glycyrrhizinic acid, given by mouth in this case, was about a thousand times the quantity of desoxycorticosterone, given by injection, which showed the same activity. To what extent this difference is caused by the different route of administration and poor absorption is another question for further investigation.

\section{SUM MARY}

A case of Addison's disease is described in which, after the administration of desoxycorticosterone was stopped, electrolyte equilibrium was maintained by the daily administration of 3-4 grams of ammonium glycyrrhizinate by mouth. On withdrawal of the glycyrrhizinate administration the patient responded by sodium and chloride loss, potassium retention, and clinical signs of dehydration and hemoconcentration. Administration of crude licorice extract brought the electrolyte metabolism back to normal. This observation seems to prove that glycyrrhizinic acid is the active principle through which crude extract of licorice exerts its influence on the electrolyte metabolism in Addison's disease.

\section{REFERENCES}

1. Molhuysen, J. A., Gerbrandy, J., de Vries, L. A., de Jong, J. C., Lenstra, J. B., Turner, K: P., and 
Borst, J. G. G., A liquorice extract with desoxycortone-like action. Lancet, 1950, 2, 381.

2. Groen, J., Pelser, H., Willebrands, A. F., and Kamminga, C. E., Extract of licorice for the treatment of Addison's disease. New England J. Med., 1951, 244, 471.

3. Robinson, J. F., Power, M. H., and Kepler, E. J., Two new procedures to assist in the recognition and exclusion of Addison's disease; preliminary report. Proc. Staff Meet. Mayo Clinic, 1941, 16, 577.

4. Thorn, G. W., Forsham, P. H., Prunty, F. T. G., and
Hills, A. G., Test for adrenal cortical insufficiency; response to pituitary adrenocorticotropic hormone. J. A. M. A., 1948, 137, 1005.

5. Bergmann, F., Uber das enzymatische Verhalten von Glucuroniden und über Glycyrrhizinsäure. Biochem. Ztschr., 1933, 267, 296.

6. Ruzicka, L., and Leuenberger, H., Zur Kenntniss der Glycyrrhetinsäure. Helvet. chim. Acta, 1936, 19, 1402.

7. Ruzicka, L., Zur Kenntniss der Glycyrrhetinsäure. Helvet. chim. Acta, 1943, 26, 2278. 